\title{
Conference report: Community media at ECREA's ECC08
}

Salvatore Scifo

European Union Institute, Marmara University/

Communication and Media Research Institute, University of Westminster

On 25-28 November 2008 the second European Communication Conference (ECC08) took place in Barcelona hosted by the Autonomous University of Barcelona (UAB). The event, arguably the most important European conference reuniting communication and media researchers from all across Europe, featured over 750 presentations distributed among 140 sessions. Among these a wide range of papers on community media were presented, spread across two thematic sections, Communication and Democracy, and Radio Research.

In the Radio Research section, the three panels Community Radio, People, Participation and Practice; Radio Audiences and Listening and Radio, Identity and Politics, included a wide range of papers on community radio practice and contexts.

The first panel, moderated by Rosemary Day (author, among others, of two recent publications on community radio in Ireland (Day 2008a, 2008b)), featured perspectives from Austria, Belgium, Germany, cross-border areas of France and Spain, and a case study from Burkina Faso.

The Austrian study, authored by Brigitta Busch, Judith Purkarthofer and Petra Pfisterer, all from the University of Vienna, focused on the role played by community radio towards social cohesion. The research was aiming to answer questions as: How do people get involved with radio? Why do they start their radio work and why are they staying? Which effects does this activity have for the individuals and how does their environment take into account their commitment?

The overall context of limited financial and structural resources, in the case of Austria, was also taken into account. The results showed a powerful positive impact on all the interviewed volunteers and members of staff. However, their participation was also influenced by power relations, in terms of gender, class, ethnicity, present in the Austrian society and special care needed to be given to prevent hegemonic practices to be enacted in the 15 community radio stations that were part of the sample.

The outcomes of this research would be surely interesting to be discussed further in comparative studies or compared with research that used qualitative methods to assess the impact of community radio (as Australia, see Meadows at al. 2007)

The empowering potential of community radio for women was also highlighted by Etienne 
Damome, University of Bordeaux 3, who analysed the case study of Radio Munyu, based in Banfora, Burkina Faso and its contribution to reconfigure the local public sphere. She explored the effects of local communication tools directed by women, the social development model that they proposed and how self-promotion, information and awareness campaigns were managed, discussing the functions of the democratization of communication, the empowerment of women and the social development induced by their actions in radio programming. The findings of the study did confirm that through their participation in the community radio station, the women involved in the project did contribute to the creation of a more pluralistic public sphere and to the possibilities of constructing legitimacy in a social system characterised by strong gender disparities (Damome, 2008: 10)

Concepts of participation put in practice in two community radio station in the Belgian capital of Brussels (Radio Panik and Radio Air Libre), and the position of these media within debates on citizenship, were the issues explored by Maaika Santana (Free University of Brussels). She analysed how participation is organised in both stations at the levels of media content production and decision-making processes. The presentation was concluded by asking the question of if, and how, concepts of Brussels citizenship and the democratic-communicative city are presented through the practices and the discourses of the two stations, which becomes especially important because of the absence of a common policy towards (media and linguistic) democracy in the Brussels capital region. This case study was further developed in order to provide the empirical basis for the analysis of alternative-rhizomatic networks in this issue (see Santana and Carpentier's article).

The complexity of the policy and regulatory framework for community radio in Germany, as Hans Kleinsteuber (University of Hamburg) clearly outlined, is arguably the main cause of its underdevelopment, if compared with the lively environments in the neighbouring countries of France, Netherlands and Denmark. The main reason of this situation is the fact that the competence for media policy in each of the Federal States (Länder) that compose Germany is devolved to themselves, where the central government is only responsible for international broadcasting. The practical result of this is a very diverse landscape of community radios across the states: Some have rather lively radio activities and others do not have any. The over three hundred stations in this category are also named differently, depending on the tradition of each state: 'non-commercial' and 'citizen media' (Bürgermedien), 'educational radio', 'university radio', and sometimes also the Open Channels (Offene Kanäle) are included in this list. Kleinsteuber (online, 2008) argued that the main reason for this situation in Germany is 'the tradition of the strong state, which makes it very difficult for the political elite to think of radio stations being controlled by ordinary people - or even worse: 
movements established by critical citizens, rebellious students or migrants' (ibid.).

Finally, the paper of Pascal Ricaud (University François Rabelais, Tours) analysed the practice of community radio stations operating in the cross-borders areas of France and Spain. He outlined how these stations have contributed to a regional and trans-border cultures revival, as well as a revaluation of local places and diversity, and the intensification of the ties, exchanges and flows between these neighbouring regions in the context of the European Union. The paper was based on a research that studied the emerging media spaces and the actors of the territorial and cultural interactions in these areas between 1996 and 2003 and included also the discussion of web-based community radio case studies more recently published in academic literature (Gusse 2006, Peñafiel Saiz 2008). Ricaud argued that community radio stations "appear as much as media of reliance than as defiance, leaning on world representations from which they produce ethno-speeches reflecting rebuilt realities assimilated to the specific communities they represent" (online, 2008). Through the analysis of stations' case studies, he also illustrated how the notion of community takes new forms, more and less disconnected from the territory, highlighting the emergence of public micro-spaces on the borders, especially through on-line community radio stations that are able to appeal to groups that cannot be reached through traditional FM broadcasting in those areas.

Moving to the panel Radio Audiences and Listening, here, only one presentation researching community media was included. This was the paper by Sebastien Poulain (Paris 1 University) who explored the issue of community radio and audience measurement in France. As it is the case almost everywhere across the world (with the notable exception of Australia, see Community Broadcasting Association of Australia, online, 2008), little information on the audience numbers of community radio is available in France. For the mainstream media, Médiamétrie measures and regulates the definition of "audience" in France. The survey gives aggregate listening figures about the whole sector, and community radio stations have an estimated $1 \%$ share at the national level, but not for individual stations. Sustaining the costs to participate to the Médiamétrie survey is anyway prohibitive for them and, moreover, giving that community radio stations in France usually do not depend significantly from advertising revenues, this is not currently seen as the most pressing concern. However, Poulain remarked, community radio stations are becoming more expensive to run due to an increasing professionalization of their news content and will need to find new ways to fund news production at their stations. Therefore, if they decide to appeal to potential investors and advertisers they would need to have more concrete data. Moreover, also others have been asking these figures, like the members of the French Senate, questioning the impact of the 25 million Euro distributed to a number of station through the French community fund FSER (Fonds de Soutien à 
l'Expression Radiophonique). Where audience measurement has not be considered in the history of community radio stations in France, Poulain warned that this might need to become the case in the near future and that the sector would need to plan future activities in this area.

The last panel that featured community radio research was Radio, Identity and Politics. Eleanor Shember-Critchley (Manchester Metropolitan University) presented an initial analysis of ethnic minority radio and audience identity in the United Kingdom, based on her research of a sample of stations including a public national DAB station (BBC Asian Network), a local commercial station (the programme Somali on Air at Spectrum Radio, London), a DAB talk radio station (Colorful Radio, London) and a community radio station (Radio Asian Fever, Leeds). The research uses a qualitative approach utilising interview, observation, listening diaries and focus groups. Giddens' theory of structuration (1984) is employed to address the two main aspects of the research: a) an examination of the stations, relevant media institutions and their digital and analogue operating environment; b) an investigation of the relevant agents which interact to reproduce and sustain these structures. Among other things, her research demonstrates how Radio Asian Fever in Leeds has become a regular listening appointment for the South Asian community in inner city Leeds, particularly for women and the older generations. A quote from the interview with the station's manager is telling in this respect, when he recounts a female listener who

"doesn't have a lot of family and a lot of people that she knows here, she's new and the fact that she's been listening and she's been listening to these people being mentioned, these people talking to each other and these people dedicating songs to each other, they don't even know each other but they act as if they're big brothers and sisters towards each other and she says 'it's like I don't have to leave the house to feel that I belong somewhere"' (ShemberCritchley, 2008:9)

Start-up and running costs of a full-time station can be prohibitive for smaller ethnic groups, and in the case of the geographically dispersed Somali community in the UK this has meant setting up programming slots at multicultural stations, including the local commercial broadcaster Spectrum Radio. The enormous need for Somali language based community support to address issues as family and community breakdowns has been partly filled by a number of more educated members and professionals of this ethnic group that has been giving advice and support through the programme. Shember-Critchley states that "what Radio Asian Fever and Somali on Air lack in environmental, monetary and material production resources they make up for in their grassroots knowledge of their listenership and the creativity with which they channel into the programmes" 
(ibid.,11), featuring topical debates and phone-ins, where, thanks to their internet streaming, calls are received from across Europe.

The second presentation, delivered by the author of this review, gave an overview of the development of the concept of community radio in the United Kingdom and its contemporary tensions. After a brief analysis of the main factors that have contributed to shape the definition of community radio approved by the British Parliament in July 2004, a practical example was given by discussing how community radio concepts have been interpreted on the ground using the case study of ALL FM, a station that operates in a urban, multicultural and disadvantaged area of south-east Manchester, which aims to contribute to social and cultural regeneration, as well social cohesion. Where the station provides a communicative tool to residents, as well as migrants and refugees living in the area, often underserved by the existing local media, its diversity of programming represents a challenge when searching for funding through advertising. In practice, advertising slots have an appeal limited to each single ethnic group that broadcasts from the station and is difficult to find buyers interested to appeal to a multicultural public as a whole. Moreover, at the organisational and financial level, the station's full-time staff has to spend a considerable amount of time in filling in paperwork for project funding, often of a short and medium term nature, this resulting in stretching the station's resources to its limit and making it unable to focus on long term strategies. Where the introduction of a distinct legislation for the community radio sector is surely contributing to increase the diversity of local voices across the UK, a number of multicultural stations across the country are facing a challenging financial environment: London's SoundRadio, broadcasting in over 20 languages across the East End of the city, had to hand back its FM licence also due to funding issues.

The ECREA Communication and Democracy section panels included also Perspectives on Alternative/Radical/Community media, including national case studies, as well analyses covering the European Union's communication policies. Núria Reguero Jiménez and Julián Sanmartín Navarro (both Autonomous University of Barcelona, UAB) did examine EU communication policies concerning directly or tangentially community media. A extended and revised version of this work is published in this issue (see Reguero Jiménez-Scifo's article).

The national case studies offered then the opportunity to discuss more in-depth characteristics of alternative and radical media. The Catalonia-based Òmnia Project is a initiative that includes 109 telecenters in the region, and aimed at combating digital exclusion. The presentation by Bruno Fuser, based on the results of semi-structured interviews with managers and organizers of the 
centers, illustrated how plurality is valued and a direct and intense participation of the users is achieved, taking also in account the educational paradigms developed by UNESCO and Paulo Freire, and the need to design learning processes that focus on the necessities and realities of the people involved in the projects. However, there are features that can endanger the Project: The unstable character of the work and the low salaries of organizers lead to a high turnover of labour, giving rise to a repetitive process of training and making the relationship between the professional and the institutions in the community more difficult.

A relatively recent phenomenon in Italy, Telestreets (community television channels) have been proliferating in the country since 2003, reaching 130 stations by 2006. Michela Ardizzoni (University of Colorado at Boulder) outlined the development of these ultra-local, neighbourhood stations aiming to enlarge local public spheres by giving access and means of participation to citizens living in those areas. Her study engages in the analysis of how people explore, assess, interpret, and re-define their experiences, and apply critical and imaginative thinking about the issues that confront them as citizens in the communities of place.

The starting point of the paper presented by Dimitra Milioni and Paulina Reizi Joanna Gravani (both Aristotle University of Thessaloniki, Greece) was the claim that mainstream journalism is failing to fulfil its democratic role, a criticism based on professional journalists' sourcing routines, allegedly favouring access to elite groups sources for their agenda-setting and for the framing of their news stories. Their study examined three different Greek media spheres: mainstream press, alternative online media, and the blogosphere, with the hypothesis being that the sphere of citizen journalism (including alternative online media and blogs) would differ significantly from that of the mainstream press in their agenda-setting practices, sourcing hierarchies and in offering opportunities to citizens for autonomous self-representation. By using comparative content analysis on the output of Indymedia Athens, mainstream newspapers, a sample of blogs, they explored three areas. Firstly, to what extent alternative and citizen journalism form a different agenda compared to the mainstream press; secondly, whether alternative and citizen journalism indeed privilege ordinary sources above elite sources, and, thirdly, whether ordinary people are more often portrayed and 'better' represented.

The role of Radio Marija in the social mobilization and the creation of an alternative public sphere in post-Communist Poland was the subject analysed by Izabella Zandberg (Academy for Educational Development). The station's role as an organizing force of contentious elements within the civil society of Poland was discussed. Zandberg described the participatory meaning-making 
taking place in two directions - from above, through the radio's main ideologues, and from below, through callers participating in the radio's daily open-microphone programs. Six major themes of the oppositional discourse on the airwaves of the Radio were identified and discussed: critical assessment of systemic transition, anti-elitism, ultra-Catholicism, anti-Europeanism and antiSemitism, and historicism. She (Zandberg, online, 2008) underlined the role of Radio Marija as a tool "empowering for political and social participation of the social strata that would otherwise be excluded from public involvement (the elderly, the retired)" and suggests " a possible modification of the radical media theory to consider a new factor in the formation of collective action: the medium as an initiating and organizing force" (ibid.).

Finally, French anarchist groups and their networks were examined by Richard Davis, this including the relation of anarchist cultural and political production towards the French state, the relations of the groups to themselves and the nature of their organization that is created by these connections. Because anarchist movements, Davis stated, 'are historically a political minority they must develop unique networks of organization and relations in order to maintain their presence' (2008, online). Based on interviews to members of the French anarchist networks in Paris and Rennes, the paper discussed this group's cultural production and also how current technologies are shaping the movement. Where research about these networks has been widely published in French, Davis' work will provide English speakers new material for future discussions in this area of study.

In conclusion, the panels at the ECC08 conference gave an overview of current tensions in community radio practices and contexts, remarking the contributions of stations operating in Europe and Africa to the plurality of voices available at the local level and their empowering potential for social groups often underserved by mainstream media. However, their work doesn't come without organizational and financial challenges where they are recognised as a separate sector, and it is even more difficult where such enabling policy or legislation does not exist. The discussed case studies in the areas of alternative and radical media, did then help to map out emerging practices of both progressive and conservative social movements, including television and internet-based platforms across Europe, that will surely provide elements of future discussion for researchers and practitioners alike. 


\section{References}

Community Broadcasting Association of Australia 'Community Radio National Listener Survey' Summary Report of Findings' [Online] Available at http://www.cbonline.org.au/media/McNairListners2008/FullNationalListenerSurvey2008.pdf (accessed 16 ${ }^{\text {th }}$ April 2009), 2008

Damome, E.L. 'Radios femininas en Africa y reconfiguraciòn de la esfera pùblica. El ejemplo de Radio Munyu de Banfora (Burkina-Faso)' [Online] Available at http://www.ecrea2008barcelona.org/guide/download/58.pdf (accessed 12 ${ }^{\text {th }}$ April 2009), 2008

Day, R. Community Radio in Ireland: Participation and Multi-flows of Communication, New Jersey: Hampton Press, 2008a

Day, R. Bicycle Highway: Celebrating Community Radio in Ireland, Dublin: Liffey Press, 2008b

Davis, R.E. ' Modern French Anarchist Networks' [Online] Available at: http://www.ecrea2008barcelona.org/guide/abstract.asp?id_callfor=832\&id_seccion=2\&id_sub seccio $=16$ (accessed $15^{\text {th }}$ April 2009), 2008

Giddens, A. The constitution of society: outline of the theory of structuration, Cambridge: Polity Press, 1984

Gusse, I. Diversité et indépendance des médias, Montréal: PUM; 2006

Kleinsteuber, H.J. 'Community Radio in Germany:Why is it underdeveloped?' [Online] Available at: http://www.ecrea2008barcelona.org/guide/abstract.asp?id_callfor=970\&id_seccion=13\&id_su bseccio $=114$ (accessed $15^{\text {th }}$ April 2009), 2008

Meadows, M., Forde, S., Ewart, J. and Foxwell, K. Community Media Matters: an audience study of the Australian community broadcasting sector, Brisbane: Griffith University, 2007

Penafiel Saiz, C. Transformaciones de la radio y la television en Europa (editor) Bilbao: Universidad del País Vasco, 2008

Ricaud, P. 'Community radios at the borders as revealing and actors of complex territorial and cultural restructurings in Europe' [Online] Available at http://www.ecrea2008barcelona.org/guide/abstract.asp?id_callfor=1497\&id_seccion=13\&id_ subseccio=114 (accessed 12 $2^{\text {th }}$ April 2009), 2008

Shember-Critchley, E. 'An application of Structuration theory to ethnic minority radio in the UK' [Online] Available at http://www.ecrea2008barcelona.org/guide/download/1282.pdf (accessed $12^{\text {th }}$ April 2009), 2008

Zandberg, I. 'Radical media, oppositional meaning-making and collective action: On the role of "Radio Maryja" in post-1989 Poland.' [Online] Available at http://www.ecrea2008barcelona.org/guide/download/1282.pdf (accessed 12 ${ }^{\text {th }}$ April 2009), 2008 